\title{
Correspondence
}

\section{Fibreoptic bronchoscopy and double-lumen endobronchial tubes}

To the Editor:

Alliaume et al. ${ }^{\prime}$ in their study on the use of fiberoptic bronchoscopy (FOB) after blind placement of doublelumen endobronchial tubes (DLT) cite two other studies ${ }^{2,3}$ dealing with bronchoscopic confirmation of DLT position. Pooling the data from these three studies $(n=56)$, a failure rate of $61 \%$ for left-sided DLTs $(n=41)$ and $87 \%$ for right-sided DLTs $(n=15)$ after conventional blind placement and auscultation may be calculated.

Schottke-Hennings et al. ${ }^{4}$ recently published the results of a larger $(n=110)$ prospective study dealing with this problem. Using FOB and the same criteria for correct DLT placement, they found similar failure rates. $57 \%$ (left-sided DLTs, $n=100$ ) and $80 \%$ (right-sided DLTs, $n=10$ ) of conventionally placed DLTs did not fulfill the endoscopic criteria for correct position.

Turning the patient to the lateral position may result in inadvertent flexion or extension of the neck, causing malposition of the DLT $^{5}$ (bronchial extubation or obstruction of the upper lobe bronchus). Alliaume et al. ${ }^{\prime}$ repeated $F O B$ in all patients in the lateral position but do not report their findings. Using FOB, SchottkeHennings et al. ${ }^{4}$ could demonstrate tube dislocation secondary to lateral positioning in $27 \%$ and secondary to surgical manipulation in $25 \%$ of their patients $(n=110)$.

Furthermore in the same study, fibreoptic bronchoscopy proved to be of great use in the diagnosis and management of intraoperative obstruction of the tracheal or bronchial tube lumen. Blood or coagula in $49 \%$ and secretions in $46 \%$ of the patients were verified and removed endoscopically.

Despite some opinion to the contrary, ${ }^{6}$ these studies suggest that fibreoptic bronchoscopy may play an important role in reducing the incidence of complications associated with the use of PVC-DLTs in thoracic surgery.

Stefan Zbinden MD

Department of Anaesthesia

Limmattal Hospital

Zurich-Schlieren

CH-8952 Switzerland

\section{REFERENCES}

1 Alliaume B, Coddens J, Deloof T. Reliability of auscultation in positioning double-lumen endobronchial tubes. Can J Anaesth 1992; 39: 687-90.

2 McKenna MJ, Wilson RS, Botelho RJ. Right upper lobe obstruction with right-sided double-lumen endobronchial tubes: a comparison of two types. Cardiothoracic vase Anesth 1988; 2: 734-40.

3 Smith GB, Hirsch NP, Ehrenwerth J. Placement of double-lumen endobronchial tubes. Br J Anaesth 1986; 58 : 1317-20.

4 Schottke-Hennings H, Klippe HJ, Schmieding B. Die Fiberbronchoskopie als Hilfsmittel zur Plazierung und Uberwachung von Doppellumentuben in Thoraxanasthesie. Anästhesiol Intensivmed Notfallmed Schmerzther 1989; 24: 327-33.

5 Saito S, Shuji D, Hiroshi N. Alteration of double-lumen endobronchial tube position by flexion or extension of the neck. Anesthesiology 1985; 62: 696-7.

6 Brodsy JB. Con: Proper positioning of a double-lumen endobronchial tube can only be accomplished with the use of endoscopy. J Cardiothoracvase Anesth 1988; 2: 105-9.

\section{$R E P L Y$}

Dr. Zbinden makes reference to an article of Schottke-Hennings et al. ${ }^{4}$ examinating the correlation between auscultation and $F O B$ in positioning DLTs but, unfortunately, this publication is not widely available in our country. Nevertheless, it is interesting to note that if all the available results ${ }^{l-4}$ are pooled, the discrepancy between both techniques for placement of lefisided and right-sided DLTs reaches $58 \%$ and $84 \%$ respectively. This reinforces our impression that auscultation is an unreliable method of establishing the correct position for right-and leftsided DLTs. The problem of displacement of DLTs when turning patients to the lateral position is real. ${ }^{5}$ repositioning was necessary and was performed bronchoscopically in most patients. We would add that during the study and since FOB is now our standard practice no special one-lung ventilation technique (CPAP and/or PEEP) has been necessary to counter hypoxaemia. Consequently, we recommend FOB whenever $D L T$ s are to be used because they contribute to reducing preand post-operative morbidity.

Dr. B. Alliaume

Department of Anaesthesia and Intensive Care

Onze-Lieve-Vrouw Ziekenhuis

Moorselbaan 164

9300 Aalst-Belgium 